\begin{tabular}{lll}
\hline Bentham OPEN & The Open Public Health Journal \\
\hline CrossMark & Content list available at: www.benthamopen.com/TOPHJ/ \\
\hline
\end{tabular}

RESEARCH ARTICLE

\title{
Stinging-cutting Accidents and Healthcare Waste Management's Knowledge Among Healthcare Professionals in Public Hospitals in Catania (South Italy)
}

Margherita Ferrante, Placido D’Agati, Sebastiano De Maria La Rosa, Santa A. Carini, Angela Trovato and Maria Fiore*

Department "GF Ingrassia”, University of Catania, Catania, Italy. Via Santa Sofia, 87 - 95123 Catania, Italy

Received: January 4, 2018

Revised: July 9, 2018

Accepted: July 11, 2018

\section{Abstract:}

Background:

Stinging-cutting accidents (needle-stick and sharps accidents) continue to pose a considerable environmental and occupational health risk. In Italy and in the world, the number of stinging-cutting is still unknown, primarily due to under-reporting. The inappropriate management of healthcare waste may be the cause of accidents needle-stick and sharps.

\section{Objective:}

Our aims were to evaluate the frequency and the modality of stinging-cutting accidents and to assess healthcare waste management's knowledge among nurse and auxiliary nurse of the departments where the accidents occurred.

\section{Method:}

Both a retrospective incidence study and a cross-sectional anonymous survey were conducted, during the 3-year period 2013-2015, in Catania (south Italy) public hospitals. The retrospective incidence study consisted of analysing needle-stick and sharps accidents officially reported in the records of the hospitals. Detailed information on the needle-stick and sharps accidents was analysed too. The survey consisted of assessing the knowledge of nurse and auxiliary nurses about healthcare waste management. The survey was proposed only to hospital staff in the operative units where the injuries occurred. A multiple-choice questionnaire was used for data collection regarding knowledge on healthcare waste management. Data were analysed using chi-square and Kruskal-Wallis tests, the effect size was quantified by Cramer's V.

\section{Results:}

Retrospective incidence study: needles and scalpel-blades accidents occurred in 240 health professionals, during the 3 -year period. Results show an injury rate of 1.4 per year (mean value), which decreased from 2013 to 2015 (1.8\% vs $1.2 \%$ vs $1.1 \%)$. The accidents were experienced by health professionals $(62.1 \%$ female) aged from 20 to 68 years, by nurses more than doctors $(65.8 \%$ and $18.3 \%)$ and on Wednesday (22.9\%) followed by Tuesday (17.9\%), Thursday (17.1\%), Friday (14.6\%), Monday (12.5\%), Saturday (8.8\%) and Sunday $(6.3 \%)(\mathrm{p}=0.000)$. Needle-stick accidents were more frequent than scalpels-blades accidents $(91.2 \%$ vs $8.8 \%, \mathrm{p}=0.000)$. The frequency of needles accidents was higher in nurses than in doctors (95.6\% vs. 86.4\%) while of scalpel-blades accidents, was higher among doctors compared to nurses ( $13.6 \%$ vs. 4.4\%) ( $\mathrm{p}=0.039$, Cramer's V 0.155). The most frequent site of the lesion was the left $(15.8 \%)$ and right (16.3\%) second finger. The most frequent cause of needle-stick accidents was needle puncture during medical procedure (67\%) and the most frequent cause of sharps accidents was unattended scalpel-blades (33\%). Surprisingly we have observed $4 \%$ of needle-stick accidents caused by recapping.

\footnotetext{
* Address correspondence to this author at the Department "GF Ingrassia", University of Catania, Via Santa Sofia, 87, 95123 Catania, Italy; Tel: 3995 3782188; Fax: 3995 3782177; E-mail: mfiore@unict.it
} 
Cross-sectional anonymous survey: 428 healthcare professionals completed the survey. The percentage of the correct answers to the knowledge questions for all the operative units combined (Internal Medicine, Orthopedics, Anesthesia, Surgery and Gynecology) was $70 \%$. The right way to dispose of a diaper not contaminated by blood from a patient who does not have oral-fecal infectious diseases (56\% wrong answers), the bag of urine, which does not contain traces of blood and properly emptied (64\% wrong answers), sanitary napkins in blood ( $68 \%$ wrong answers), and a IV bottle partially filled with drug ( $85 \%$ wrong answers) were identified as the most important aspects for future interventions.

\section{Conclusion:}

The study showed an underestimation of needle-stick and sharps medical accidents and lack of knowledge about healthcare waste management procedures. Future approaches are needed for providing education and training of safe handling and disposal of sharp devices, to create awareness followed by which, legislative actions would be taken.

Keywords: Hazard, Hospital, Refuses, Handling, Knowledge, Healthcare waste management.

\section{INTRODUCTION}

Medical stinging-cutting devices (needle-stick and sharps) still pose a serious occupational threat to Healthcare Workers (HCWs) because of injuries, which can expose HCWs to different bloodborne pathogens (e.g. example human immunodeficiency virus, hepatitis B virus and hepatitis C virus etc.) [1 - 3]. The World Health Organization estimated that approximately $40 \%$ of HBV and HCV infections and $2.5 \%$ of HIV infections among healthcare workers are due to medical stinging-cutting accidents [4]. Available literature on sharps injuries amongst HCWs shows widely varying numbers from 1.4 up to 9.5 (worldwide) per $100 \mathrm{HCWs}$ per year [5, 6].

Previous strategies to prevent accidents have included general training and education and the introduction of needle protection devices [7]. From 1988, many of the protective measures recommended by the Centre Diseases Control, including those related to needle disposal, have become enforceable by the Occupational Safety and Health Administration (OSHA) and the Directive 2010/32/EU (made national low in all EU countries by May 2013) which was issued to protect Healthcare Workers (HCWs) from the risk of occupational exposure and infection with bloodborne pathogens $[8,9]$. In the United Kingdom, puncture wounds and occupational transmission of blood borne pathogens have been sensitized by the Royal College of Nursing and Union for people working in Britain's Public Service (UNISON) [10]. Subsequently, the UK Department of Health recommended a drastic reduction in the use of cutting devices wherever possible and to consider the introduction of protective devices for all kinds of needles used in hospitals [11]. There is lack of evidence to show that current prevention policies are effective in reducing the impact of needle stick accidents $[12,13]$.

Few studies have estimated the incidence of reported sharps injuries $[14,15]$, and very few data are available on the health impacts of exposure to health-care waste, particularly in the case of developing countries [16 - 19]. There is no study that assesses the number and the modality of stinging-cutting accidents and healthcare waste management's knowledge among hospital staff in Sicily (South Italy).

Preventive public health policy is most effective when there is a thorough understanding of the hazard [20, 21]. In the USA, the waste management is a specific subject proposed to health facilities by the Joint Commission on Accreditation of Healthcare Organizations (JCAHO), with specific reference indicators and standards [22]. The approach used in Italy, like in the rest of the EU, is based on "waste management" focusing on the prevention and reduction of production and recovery $[23,24]$. Moreover, the current legislation gives indications that public health facilities must provide for the waste management costs [25].

Good medical waste management in hospital depends on a dedicated waste management team, good administration, careful planning, sound organization, underpinning legislation, adequate financing and full participation by trained staff [26]. Moreover, the surveillance of accidents is important to identify indications of inadequate waste-management practices. Surveillance also provides a basis for introducing control measures, assessing their efficacy, reinforcing routine preventive measures and determining the level of avoidable infection [27].

This study aims to evaluate the number and modality of stinging-cutting accidents and to assess healthcare waste management's knowledge of hospital staff of the departments where the accidents occurred. 


\section{MATERIAL AND METHODS}

\subsection{Study Settings and Data Collection}

Both a retrospective 3-year incidence study (January 2013 - December 2015) and a cross-sectional anonymous survey were conducted.

The retrospective incidence study has involved the biggest public hospitals in Catania (South Italy), without exclusion criteria.

Considering that the average number of injuries in a hospital ward is about 15 cases in 10 years [30], the occurrence of at least 5 injuries in the period examined (2013-2015) was the inclusion criteria to select the operative units for the survey.

\subsubsection{Retrospective Incidence Study}

The retrospective incidence study took into consideration only the accidents officially reported in the hospitals records. Hospital records were requested, through a letter, to the manager of each public hospital. The hospital records were used to estimate the number of accidents and to extract detailed information about accidents. In particular, operative unit, date of accident, role, age, gender, type of injury, site of the lesion and the circumstances of the accident data were acquired for each health professional involved in stinging-cutting accident. All shifts were taken into account by each hospital, both in hospital stay and operating room. The stinging-cutting accidents were divided into needles and scalpel blades. Lesions caused by cartridges and scissors were not analysed due to the poor definition of the first and the lack of accurate usage data for the latter.

\subsubsection{Cross-sectional Anonymous Survey}

The department manager of each public hospital gave the formal approval to collect data and agreed the methods for administering the questionnaire. Preliminarily, information regarding the study (purpose, protocol and methods) was provided to the participants, ensuring the confidentiality of information, including the guarantee of anonymity. Only those gave their consent to participate were admitted to the study. The questionnaire contained 16 multiple-choice questions and it was proposed to the health workers (nurse and auxiliary nurse) of the departments where the accidents occurred and those who personally deal with the management of medical waste. Data on the healthcare waste management knowledge was collected using face-to-face interview. In each answer, respondents were given 1 point for the correct answer and no point for an incorrect answer. Therefore all the correct answers have been added to calculate the mean level of knowledge for each operative unit.

\subsection{Statistical Analysis}

Statistical analysis was performed using SPSS for Windows (Statistical Package for the Social Science, version 21.0; SPSS Inc., Chicago, IL, USA). The number of accidents recorded and all healthcare personnel was used to calculate the injury rate. Categorical data were described as absolute frequencies and percentages. Continuous data were presented as mean or medians and IQR. Chi-square test was used to assess a possible association between each qualitative independent variable and stinging-cutting accidents among healthcare workers. The effect size was quantified by Cramer's V. The Kruskal-Wallis test was performed to evaluate differences for quantitative variables. The statistical significance was set at a p-value $<0.05$.

\section{RESULTS}

\subsection{Retrospective Incidence Study}

Stinging-cutting accidents (needles and scalpel blades) were experienced by 240 of 5729 exposed healthcare professionals (doctors, trainees medical, nurses, auxiliaries and laboratory technicians) with an incidence rate of 1.4 per year (mean value). Annual incidence rates were: $2013=(105) 1.8 \%, 2014=(70) 1.2 \%$ and $2015=(65) 1.1 \%(p=0.003)$.

The relationship between stinging-cutting accidents and the main characteristics of health professionals, job category, day of accident and year is reported in Table 1. In brief, the accidents experienced by health professionals $(62.1 \%$ female) aged from 20 to 68 years, in nurses more than in doctors $(65.8 \%$ and $18.3 \%)$ and on Wednesday (22.9\%) followed by Tuesday (17.9\%), Thursday (17.1\%), Friday (14.6\%), Monday (12.5\%), Saturday (8.8\%) and Sunday $(6.3 \%)(p=0.000)$. No significant differences were found in the three-year study period (Table 1). 
Table 1. Estimated frequency of stinging-cutting accidents according to main characteristics of health professionals, job category and day of accident by year.

\begin{tabular}{|c|c|c|c|c|c|}
\hline Variables & Total & $\begin{array}{c}\text { Year } 2013 \\
\mathrm{~N}=105 \\
\end{array}$ & $\begin{array}{c}\text { Year } 2014 \\
\mathrm{~N}=70\end{array}$ & $\begin{array}{c}\text { Year } 2015 \\
\mathrm{~N}=65\end{array}$ & P-Value** \\
\hline Median age in years $\left(\mathrm{IQR}^{*}\right)$ & $\begin{array}{c}48 \\
(39-55) \\
\end{array}$ & $\begin{array}{c}47 \\
(35-55) \\
\end{array}$ & $\begin{array}{c}46 \\
(38-55)\end{array}$ & $\begin{array}{c}49 \\
(43-57)\end{array}$ & 0.124 \\
\hline \multicolumn{6}{|l|}{ Gender n (\%) } \\
\hline Female & $149(62.1)$ & $65(61.9)$ & $46(65.7)$ & $38(58.5)$ & \multirow{2}{*}{0.676} \\
\hline Male & $91(37.9)$ & $40(38.1)$ & $24(34.3)$ & $27(41.5)$ & \\
\hline \multicolumn{6}{|l|}{ Job category*** n (\%) } \\
\hline Doctor & $44(18.6)$ & $21(20.4)$ & $11(15.7)$ & $12(18.8)$ & \multirow{4}{*}{0.166} \\
\hline Traianee Medical & $14(5.9)$ & $9(8.7)$ & $1(1.4)$ & $4(6.3)$ & \\
\hline Nurse & $158(66.7)$ & $62(60.2)$ & $55(78.6)$ & $41(64.1)$ & \\
\hline Auxiliary nurse & $21(8.9)$ & $11(10.7)$ & $3(4.3)$ & $7(10.9)$ & \\
\hline \multicolumn{6}{|l|}{ Day of accident $\mathrm{n}(\%)$} \\
\hline Monday & $30(12.5)$ & $14(13.3)$ & $9(12.9)$ & $7(10.8)$ & \multirow{7}{*}{0.823} \\
\hline Tuesday & $43(17.9)$ & $13(12.4)$ & $15(21.4)$ & $15(23.1)$ & \\
\hline Wednesday & $55(22.9)$ & $27(25.7)$ & $14(20.0)$ & $14(21.5)$ & \\
\hline Thursday & $41(17.1)$ & $21(20.0)$ & $11(15.7)$ & $9(13.8)$ & \\
\hline Friday & $35(14.6)$ & $14(13.3)$ & $9(12.9)$ & $12(18.5)$ & \\
\hline Saturday & $21(8.8)$ & $8(7.6)$ & $8(11.4)$ & $5(7.7)$ & \\
\hline Sunday & $15(6.3)$ & $8(7.6)$ & $4(5.7)$ & $3(4.6)$ & \\
\hline
\end{tabular}

*Interquartile range (IQR)

**Kruskal-Wallis and chi-square tests

***Laboratory technician category was excluded from the bivariate analysis because in 2014 had a frequency equal to 0 .

Needle accidents' frequency was higher than accidents by scalpels blades $(91.3 \%$ vs. 8.8\%, $\mathrm{p}=0.000)$. We have found a weak association between injury (needles and scalpel blades) and job (nurses and doctors) categories ( $\mathrm{p}=0.039$, Cramer's V 0.155 ), which may explain $2.4 \%$ of the variance. In particular, needle accidents' frequency was higher in nurses than in doctors $(95.6 \%$ vs. $86.4 \%)$ whereas the frequency of scalpel blades accidents was higher among doctors compared to nurses $(13.6 \%$ vs. $4.4 \%)$ The bivariate analysis that assessed the association between stinging-cutting accidents and the other job categories (Trainee Medical, Laboratory technician and Auxiliary nurse) did not report significant association (data not showed).

No significant association was found between stinging-cutting accidents and operative units: anaesthesia (17.8\%) surgery/operating room (17.8\% and 18.5\%), genecology (5.2\%), nephrology (5.9), orthopaedics (4.4\%), emergency room $(13.3 \%)$.

The relationship between the operative units in which the stinging-cutting accidents occurred and job categories was not analysed because the assumption of the chi-square test was not satisfied: seven cells (38.9\%) were expected to have count less than 5 and the minimum expected count was 0.50 .

Comparing the frequency of accidents (needles and scalpel blades) in terms of year among the operative units, we found no significant trend reduction in anesthesia $(2013=54.2 \%, 2014=25.0 \%, 2015=20.8 \%)$, internal medicine $(2013=58.3 \%, 2014=25.0 \%, 2015=16.7 \%)$ and nephrology $(2013=62.5 \%, 2014=25.0 \%, 2015=12.5 \%)$.

The most frequent site of the lesion was the left (15.8\%) and right (16.3\%) second fingers. Only the right second finger injuries had an increasing trend in the study period (2013: 13.3\%, 2014: 15.7\%, 2015: 21.5\%).

The most frequent cause of needle-stick injuries was needle puncture during medical procedure $(67 \%)(2013$ : 64.8\%, 2014: 65.7\%, 2015:57.5\%) followed by unattended suture needle (13.3\%) (2013: 12.4, 2014:18.6, 2015:9.2\%) and disposal of suture needle (12.9\%) (2013: 11.4\%, 2014: 12.9\%, 2015:15.4\%).

The most frequent cause of sharps medical accidents was unattended scalpel-blades (33\%) (2013: 3.8\%, 2014: $1.4 \%, 2015: 3.1 \%)$ followed by medical-surgical procedure (3.3\%) (2013: 1.9\%, 2014:1.4\%, 2015:7.7\%) and disposal of scalpel blades (0.4\%) (2013 and 2014: 0\%, 2015: 1,5\%).

Surprisingly we have found 4\% (2013: 5,7\%, 2014: 0\%, 2015: 4,6\%) of needle-stick accidents happened during recapping. 
For the aforementioned analyses, they were no reported p-values because most of the categories had a frequency near to 0 .

\subsection{Cross-sectional Anonymous Survey}

Out of 3050-exposed health professionals (nurses and auxiliaries) 428 (14\%) completed the survey. The questions and the wrong answers of the survey about health professionals' knowledge are reported in Table 2.

Table 2. Wrong answers to the 16 item of the questionnaire used for the survey.

\begin{tabular}{|c|c|}
\hline Questions & $\begin{array}{c}\text { Wrong Answers } \\
\text { n (\%) }\end{array}$ \\
\hline 1. What is the right way to dispose of a blood strained bandage? & $7(2)$ \\
\hline 2. What is the right way to dispose of a bag full of urine with visible traces of blood? & $28(7)$ \\
\hline 3. What is the right way to dispose of a syringe after performing an injection? & $31(7)$ \\
\hline 4. What is the right way to dispose of a placenta? & $109(25)$ \\
\hline $\begin{array}{l}\text { 5. An empty IV bottle not contaminated by biological waste used for a patient with the diagnosis of suspect appendicitis has been } \\
\text { removed. What is the right way to dispose of it? }\end{array}$ & $161(38)$ \\
\hline $\begin{array}{l}\text { 6. A diaper not contaminated by blood from a patient who does not have oral-fecal infectious diseases has been removed. What is } \\
\text { the right way to dispose of it? }\end{array}$ & $241(56)$ \\
\hline 7. What kind of waste are amputated limbs classified? & $95(22)$ \\
\hline 8. What is the right way to dispose of the gloves used by the gynecologist during a visit? & $112(26)$ \\
\hline 9. What is the right way to dispose of the gloves used but not contaminated by body fluids? & $179(42)$ \\
\hline 10. What is the right way to dispose of the bag of urine, which does not contain traces of blood and properly emptied? & $273(64)$ \\
\hline 11. What is the right way to dispose of sanitary napkins from blood? & $289(68)$ \\
\hline 12. What kind of waste are expired medical products classified? & $81(19)$ \\
\hline 13. What kind of waste are expired drugs/medicines classified? & $203(47)$ \\
\hline 14. What is the right way to dispose of hazardous medical waste at risk of infection, which is not stinging or cutting? & $51(12)$ \\
\hline 15. What is the right way to dispose of an IV bottle partially filled with drug? & $363(85)$ \\
\hline 16. What is the right way to dispose of a plaster cast removed from a limb not contaminated with blood? & $121(28)$ \\
\hline
\end{tabular}

The operative unit of anesthesia had the highest percentage of correct answers (81\%) but the lowest adhesion rate to the survey $(11 \%)$. The operative unit of surgery had the highest frequency of accidents $(32.7 \%)$, a percentage of correct answers equal to $70 \%$ and an adhesion rate equal to $13 \%$ (Table 3 ).

Table 3. Total nurses and auxiliaries, response rate, accidents and correct answers frequency by operative unit.

\begin{tabular}{|l|c|c|c|c|}
\hline Operative Units & Total Nurses and Auxiliaries & $\begin{array}{c}\text { Response Rate } \\
\mathbf{n}(\%)\end{array}$ & $\begin{array}{c}\text { Accidents Frequency } \\
\text { (\%) }\end{array}$ & $\begin{array}{c}\text { Correct Answers } \\
\text { (\%) }\end{array}$ \\
\hline Internal medicine & 466 & $65(14)$ & 24.5 & 70 \\
\hline Orthopedics & 724 & $99(14)$ & 6.1 & 63 \\
\hline Anesthesia & 676 & $71(11)$ & 28.6 & 81 \\
\hline Surgery & 880 & $111(13)$ & 32.7 & 70 \\
\hline Gynecology & 304 & $45(15)$ & 8.2 & 70 \\
\hline
\end{tabular}

\section{DISCUSSION}

In our study, only $4.2 \%$ of the healthcare workers reported having an accident, from January 2013 to December 2015, with a significant decreasing annual incidence rates. The reported incidence of sharps injuries in literature ranges widely from 1.4 to 9.5 per 100 healthcare workers per year; therefore the underestimation of accidents could be a widespread concern [27 - 29]. Lynn Y. Choi et al. have found several reasons why healthcare workers do not report accidents: because of time, due to fear, surgical culture etc [28].

According to Puro V. et al. in our study, the most accident-prone operative units were observed to be surgery and anaesthesia, needle-stick injuries were more frequent than scalpel injuries, and nurses and doctors are more affected than other job category [30].

Moreover, previous studies and our results point out that the most frequent causes of needle-stick and sharps medical accidents were needle puncture during medical procedure and unattended scalpel blades, respectively [31].

Devices have provided health care professional with a new opportunity to reduce injuries but also the safest devices 
are not always protective, and they often rely on the correct use [32]. We found 4\% of needle-stick accidents because of re-capping. Despite having the knowledge of safety measures by $97 \%$ staff, in practice, they are only partially adopted. For example the re-capping of used needles continues to be one of the most risky operations still practiced $(17 \%$ of cases) [33]. These results may suggest that needle-stick accidents would be representing a realistic aim for our hospitals; moreover, compliance with Universal Precautions is essential if prevention by vaccination is not possible [34].

The most accidents (75.5\% of accidents) are related to inattentiveness, fatigue, stress, nurses' sense of urgency, variable shift work, and lower skill level related to years of experience, academic degree and younger age [35, 36]. The increase in workloads of health workers and the introduction of increasingly complex diagnostic and therapeutic procedures can also explain this trend. A cross-sectional study, involving nurses and specialized clinical coordinators, highlighted a tendency to underestimate the occupational risks [37].

Our results are in agreement a study reported in the literature. It is therefore necessary to investigate the circumstances of the accidents, the habits and behaviours of health workers, in order to identify the weaknesses which can be dealt by implementing a series of organizational and educational measures aimed at reducing the incidence of injuries. In addition, injuries represent not only health risk for health workers, but also an economic problem. In Italy, the average cost of diagnosis, prophylaxis and post-exposure monitoring is around $€ 850$ per event (range 750-1320 Euro) $[38-40]$.

Our survey and previous studies revealed a number of critical issues related to the health waste classification and management practices [41]. None of the surveyed operative units had good knowledge about the right way to dispose off healthcare waste. The knowledge of the clinical risk and its governance allows the operators to think according to prevention logic, it would allow to act on risk factors such as stress, fatigue and inattention, excessive workloads and adequate placement of the cutting disposal containers. Unfortunately, the lack of training on the subject is increasing instead the training should be an important variable in the context of the mandatory update of health workers. Caciari et $a l$. confirm that the correct use of personal protective equipment, training and information of workers and observance of universal precautions are effective for their protection [42].

Therefore, organizational and educational measures implemented in order to reduce accidents must include both the training/information of health workers and the correct use of protection devices. It is also essential that the formation is continuous and in step with progress [43], the involvement of the personnel of various sectors and disciplines in the planning and implementation of the activities, improves the culture of safety that is essential for the success of this initiative [44].

This retrospective incidence study has several limitations. Injury rate was calculated using all personnel so we underestimate the overall risk by including those who have little or no risk of stinging-cutting accidents. We did not take into account multiple injuries and the study was based on accidents officially reported, so it may affect the calculation of incidence rate and it is does not allow to comment on the number of non-reported cases. It is known from the literature that about $27 \%$ of the accidents were not reported because the item was unused and $7 \%$ were unreported because the incident was considered to be "minor" [45]. Moreover, our results showed differences in the frequency of injuries on weekdays, but we do not have information about the causes whose knowledge might be important for future interventions aimed at reducing accidents. Furthermore, the cross-sectional study design precludes causal inference for the relationship between stinging-cutting accidents and the knowledge about healthcare waste management.

The survey has limitations too. The major limitation is the small sample size, which makes it difficult to perform subgroup analyses. This was because of a relatively low response rate, which can be characteristic of survey-based studies. A future direction is a larger multicentre study to produce suitable data analyses with a sufficient statistical power useful to highlight what could be done next to improve health professional training. Moreover, we did not take into account years of experience as health professionals, long work hours and no information is available regarding the content of the training sessions in each work-place.

Finally, we investigated only the biggest public hospitals of Catania, so our results may not be representative of all hospitals.

\section{CONCLUSION}

In conclusion, continuous monitoring and training programs are needed to reduce the hazards to healthcare workers, moreover protecting the health of healthcare workers is critical to preserving the healthcare system. The results of this 
study provide a basis for the stinging-cutting accidents control in the hospital and for health administration department to establish the policies for safe Healthcare Waste Management.

\section{ETHICAL APPROVAL AND CONSENT TO PARTICIPATE}

The department manager of each public hospital gave the formal approval to collect data and agreed the methods for administering the questionnaire.

\section{HUMAN AND ANIMAL RIGHTS}

No animals/ humans were used for the studies that are bases of this research.

\section{CONSENT FOR PUBLICATION}

Informed written consent was obtained from all the participants involved in study.

\section{CONFLICT OF INTEREST}

The members of this group declared that they have no competing interest.

\section{ACKNOWLEDGEMENTS}

Declared none.

\section{REFERENCES}

[1] Prüss-Ustün A, Rapiti E, Hutin Y. Estimation of the global burden of disease attributable to contaminated sharps injuries among health-care workers. Am J Ind Med 2005; 48(6): 482-90.

[http://dx.doi.org/10.1002/ajim.20230] [PMID: 16299710]

[2] De Carli G, Abiteboul D, Puro V. The importance of implementing safe sharps practices in the laboratory setting in Europe. Biochem Med (Zagreb) 2014; 24(1): 45-56. [http://dx.doi.org/10.11613/BM.2014.007]

[3] Ruijs WL, Timen A. Guideline 'Needlestick injuries': Risk assessment and post-exposure management in practice. Ned Tijdschr Geneeskd 2008; 152(36): 1967-71. [PMID: 18807333]

[4] World Health Organization The world health report 2002: Reducing risks, promoting healthy life World Health Organization 2002.

[5] Matsubara C, Sakisaka K, Sychareun V, Phensavanh A, Ali M. Prevalence and risk factors of needle stick and sharp injury among tertiary hospital workers, Vientiane, Lao PDR. J Occup Health 2017; 59(6): 581-5. [http://dx.doi.org/10.1539/joh.17-0084-FS] [PMID: 28904259]

[6] Elseviers MM, Arias-Guillén M, Gorke A, Arens HJ. Sharps injuries amongst healthcare workers: Review of incidence, transmissions and costs. J Ren Care 2014; 40(3): 150-6. [http://dx.doi.org/10.1111/jorc.12050] [PMID: 24650088]

[7] Valls V, Lozano MS, Yánez R, et al. Use of safety devices and the prevention of percutaneous injuries among healthcare workers. Infect Control Hosp Epidemiol 2007; 28(12): 1352-60. [http://dx.doi.org/10.1086/523275] [PMID: 17994515]

[8] Recommendation for the prevention of HIV transmission in health care settings. MMWR 1987; 36(2): 1-18. [PMID: 2824976]

[9] Council Directive 2010/32/EU of May 2010 implementing the Framework Agreement on prevention from sharp injuries in the hospital and healthcare sector concluded by HOSPEEM and EPSU. Off J. Eur Union 2010; L134: 66-72.

[10] Be Sharp-be Safe: Avoiding the Risks of Sharps Injury. Working Well Initiative RCN 2001.

[11] Department of Health Guidance for Clinical Healthcare workers Protection against infection with blood-borne viruses, Recommendations for the Expert Advisory Group on AIDS and the Advisory Group on Hepatitis DoH. 1998.

[12] Crema M, Verbano C. Lean Management to support Choosing Wisely in healthcare: The first evidence from a systematic literature review. Int J Qual Health Care 2017; 29(7): 889-95. [http://dx.doi.org/10.1093/intqhe/mzx135] [PMID: 29045684]

[13] Hatano Y. [With the introduction of Infection Control Committees in mid-sized private hospitals, cutting-edge accident prevention methods and solutions will be utilized to reduce the impact of needlestick accidents]. Rinsho Byori 2012; 60(10): 990-6. [PMID: 23323466]

[14] Kocur E, Śliwa-Rak BO, Grosicki S. Analysis of occupational exposures to blood registered in the General Hospital in Zabrze in the years 2006-2015. Przegl Epidemiol 2016; 70(4): 603-15. 
[PMID: 28233963]

[15] Gu Y, Chen C, Cheng KP, Tu ZB, Zhang XJ. Analysis of needlestick and sharps injuries among medical staff in upper first-class hospital. Zhonghua Lao Dong Wei Sheng Zhi Ye Bing Za Zhi 2013; 31(1): 41-4. [PMID: 23433157]

[16] Oyekale AS, Oyekale TO. Healthcare waste management practices and safety indicators in Nigeria. BMC Public Health 2017 ; $17(1)$ : 740. [http://dx.doi.org/10.1186/s12889-017-4794-6] [PMID: 28946876]

[17] Udofia EA, Gulis G, Fobil J. Solid medical waste: A cross sectional study of household disposal practices and reported harm in Southern Ghana. BMC Public Health 2017; 17(1): 464.

[http://dx.doi.org/10.1186/s12889-017-4366-9] [PMID: 28521776]

[18] Ali Mustafa, Wang Wenping, Chaudhry Nawaz. Management of wastes from hospitals: A case study in Pakistan Management and research. 2016. [http://dx.doi.org/10.1177/0734242X15616474]

[19] Sobia M, Batool SA, Chaudhry MN. Characterization of hospital waste in Lahore, Pakistan. Chin Med J (Engl) 2014; 127(9): 1732-6. [PMID: 24791883]

[20] Ferrante M, Fiore M, Fallico G, et al. A ten-year risk evaluation study in Catania hospital operating rooms. Ig Sanita Pubbl 2004; 60(1-2): 39-50. [PMID: 15213759]

[21] D'Alessandro D, Agodi A, Auxilia F, et al. Prevention of healthcare associated infections: Medical and nursing students' knowledge in Italy (2014) Nurse Education Today. 2014; 34.(2)

[22] Garvin ML. Infectious waste management. UK: A practical guide CRC Press 1995.

[23] DPR 30 settembre 2013, n 0185 Linee guida regionali per la gestione dei rifiuti sanitari GR n0185/Press Regione Autonoma Friuli Venezia Giulia. Agosto 2013.

[24] Dlgs 3 aprile 2006, n 152 "Norme in materia ambientale", parte terza e quarta, "Norme in materia di gestione dei rifiuti e di bonifica dei siti inquinati" GU n 88 del 14 aprile. 2006.

[25] DPR 15 luglio 2003, n254 Regolamento recante disciplina della gestione dei rifiuti sanitari a norma dell'articolo 24 della legge 31 luglio. 2003.

[26] Preparation of National Healthcare Waste Management Plans in sub-Sahara countries. 2005.

[27] Safe management of wastes from healthcare activities. 2014.

[28] Dulon M, Lisiak B, Wendeler D, Nienhaus A. Causes of needlestick injuries in three healthcare settings: Analysis of accident notifications registered six months after the implementation of EU Directive 2010/32/EU in Germany. J Hosp Infect 2017; 95(3): 306-11. [http://dx.doi.org/10.1016/j.jhin.2016.11.015] [PMID: 28034473]

[29] Lynn Y. Choi, MD, Rosalicia Torres, MD, Sohail Syed, MD, Sean Boyle, MD, Ashar Ata, MPH, Todd D. Beyer, MD and Carl Rosati. Sharps and Needlestick Injuries Among Medical Students, Surgical Residents, Faculty, and Operating Room Staff at a Single Academic Institution. J Surg Educ 2016.

[http://dx.doi.org/10.1016/j.jsurg.2016.06.003]

[30] Puro V, De Carli G, Petrosillo N, Ippolito G. Risk of exposure to bloodborne infection for Italian healthcare workers, by job category and work area. Infect Control Hosp Epidemiol 2001; 22(4): 206-10. [http://dx.doi.org/10.1086/501890] [PMID: 11379710]

[31] Castella A, Vallino A, Argentero PA, Zotti CM. Preventability of percutaneous injuries in healthcare workers: A year-long survey in Italy. J Hosp Infect 2003; 55(4): 290-4.

[http://dx.doi.org/10.1016/j.jhin.2003.08.013] [PMID: 14629973]

[32] Needlestick Injuries: Sharpen your awareness Report of the short life working group on needlestick injuries in the NHS scotland. Scottish Executive 2001.

[33] Merino-de la Hoz F, Durá-Ros MJ, Rodríguez-Martín E, et al. Knowledge and adherence to bio-safety measures and biological accidents by nursing students during their clinical practice. Enferm Clin 2010; 20(3): 179-85.

[http://dx.doi.org/10.1016/j.enfcli.2009.10.007] [PMID: 20116309]

[34] Ministry of Italian Health Decree 28/9/90: Rules for the prevention of professional HIV infection in public and private health and care facilities (The Universal Precautions)].

[35] Cicolini G, Di Labio L, Lancia L. Prevalenza delle esposizioni biologiche tra gli studenti infermieri: Studio osservazionale. Prof Inferm 2008; 61(4): 217-22. [PMID: 19250618]

[36] Rohde KA, Dupler AE, Postma J, Sanders A. Minimizing nurses' risks for needlestick injuries in the hospital setting. Workplace Health Saf 2013; 61(5): 197-202. [http://dx.doi.org/10.3928/21650799-20130418-24] [PMID: 23650894]

[37] Porras-Povedano M, Santacruz-Hamer V, Oliva-Reina I. Occupational risks perception in professional nursing practitioners at health care center. Enferm Clin 2014; 24(3): 191-5. 
[http://dx.doi.org/10.1016/j.enfcli.2013.11.002] [PMID: 24529895]

[38] Cazzaniga S, De Carli G, Sossai V, et al. Il costo delle ferrite accidentali da aghi e l'impatto dei dispositive di sicurezza per la prevenzione dal rischio di punture accidentali. Mecosan 2006; 15: 99-116.

[39] Mannocci A, De Carli G, Di Bari V, et al. How much do needlestick injuries cost? A systematic review of the economic evaluations of needlestick and sharps injuries among healthcare personnel. Infect Control Hosp Epidemiol 2016; 37(6): 635-46.

[http://dx.doi.org/10.1017/ice.2016.48] [PMID: 27022671]

[40] Elseviers MM, Arias-Guillén M, Gorke A, Arens HJ. Sharps injuries amongst healthcare workers: Review of incidence, transmissions and costs. J Ren Care 2014; 40(3): 150-6.

[http://dx.doi.org/10.1111/jorc.12050] [PMID: 24650088]

[41] Blenkharn JI. Potential compromise of hospital hygiene by clinical waste carts. J Hosp Infect 2006; 63(4): 423-7.

[http://dx.doi.org/10.1016/j.jhin.2006.03.002] [PMID: 16759738]

[42] Caciari T, Casale T, Tomei G, et al. Biological risk among health workers. G Ital Med Lav Ergon 2013; 35(3): 163-7. [PMID: 24734323]

[43] Brusaferro S, Calligaris L, Farneti F, Gubian F, Londero C, Baldo V. Educational programmes and sharps injuries in health care workers. Occup Med (Lond) 2009; 59(7): 512-4.

[http://dx.doi.org/10.1093/occmed/kqp112] [PMID: 19706644]

[44] Workbook for designing, Implementing and Evaluating a Sharps and Injury Prevention Program Available from: http://www.ede.gov/sharpssafety/pdf/sharpsworkbook_2008.pdf

[45] Smith DR, Choe MA, Jeong JS, Jeon MY, Chae YR, An GJ. Epidemiology of needlestick and sharps injuries among professional Korean nurses. J Prof Nurs 2006; 22(6): 359-66.

[http://dx.doi.org/10.1016/j.profnurs.2006.10.003] [PMID: 17141720]

(C) 2018 Ferrante et al.

This is an open access article distributed under the terms of the Creative Commons Attribution 4.0 International Public License (CC-BY 4.0), a copy of which is available at: https://creativecommons.org/licenses/by/4.0/legalcode. This license permits unrestricted use, distribution, and reproduction in any medium, provided the original author and source are credited. 